\title{
Statistical Modelling of Recent Changes in Extreme Rainfall in Taiwan
}

\author{
Lan-Fen Chu, Michael McAleer, and Szu-Hua Wang
}

\begin{abstract}
This paper has two primary purposes. First, we fit the annual maximum daily rainfall data for 6 rainfall stations, both with stationary and non-stationary generalized extreme value (GEV) distributions for the periods 1911-2010 and 1960-2010 in Taiwan, and detect changes between the two phases for extreme rainfall. The non-stationary model means that the location parameter in the GEV distribution is a linear function of time to detect temporal trends in maximum rainfall. Second, we compute the future behavior of stationary models for the return levels of 10, 20, 50 and 100-years based on the period 1960-2010. In addition, the $95 \%$ confidence intervals of the return levels are provided. This is the first investigation to use generalized extreme value distributions to model extreme rainfall in Taiwan.
\end{abstract}

Index Terms - Extreme rainfall, generalized extreme value, return level, statistical modeling.

\section{INTRODUCTION}

Extreme rainfall is one of the main causes of natural disasters, especially in flood hazards worldwide. Not surprisingly, considerable attention has been paid in recent years to the modelling of extreme rainfall to help prevent flooding hazards, and for analysing water-related structures, agriculture, and monitoring climate changes.

Taiwan is a small island in East-Asia. An average of 3.5 typhoons strike Taiwan each year, often in summer and autumn, and cause significant damage, especially in highly concentrated population and property areas. In the past few years, the Kalmaegi and Sonlaku Typhoons in 2008 and Morakot Typhoon in 2009 have brought to Taiwan many casualties and serious injuries. Morakot Typhoon struck Taiwan from 7-9 August 2009 with abundant rainfall, reaching $2,777 \mathrm{~mm}$, and surpassing the historical record of Typhoon Herb, which had brought rainfall of $1,736 \mathrm{~mm}$ ([1];[2]). The extremely heavy rainfall triggered severe flooding (the worst in the past 50 years) and enormous mudslides throughout southern Taiwan, leading to around 700 deaths and roughly NT $\$ 110$ billion in property damage ([3]).

More typhoons seem to have affected Taiwan after 1990 than between 1961-1989 (see [5]), and increased sharply around 2000 (see [6]). Such an indication of increasing frequency and intensity of rainfall means that Taiwan will

Manuscript received December 2, 2012; revised February 3, 2013.

Lan-Fen Chu is with the National Science and Technology Center for Disaster Reduction (NCDR) (e-mail: lanfen.chu@gmail.com)

Michael McAleer is with Econometric Institute, Erasmus School of Economics, Erasmus University Rotterdam, The Netherlands.

Szu-Hua Wang is with the Department of Urban Affairs and Environmental Planning at Chinese Culture University, Taiwan. face a higher probability of huge damages from extreme rainfall in the future. Thus, understanding the patterns of extreme rainfall and their future behaviour is of increasing importance to policy makers in Taiwan.

Several published papers have analysed extreme rainfall using the generalized extreme value (GEV) distribution in different parts of the world, including Canada[7], [8]; Greece [9]; India [10], [11]; Italy [12]-[14]; Malaysia [15]; New Zealand [16]; China [17]; Korea [18], [19], and West Central Florida [20]. These findings highlight the urgency to model extreme rainfall using the GEV distribution. However, there would seem to have been little or no published research that has attempted to detect extreme rainfall by using GEV. Therefore, this paper would seem to be the first application of the GEV distribution for extreme rainfall in Taiwan. We believe that such an analysis can provide a useful reference for climate change in the research of extreme rainfall.

\section{DATA}

The data consist of daily rainfall records for the years 1911-2010, which were provided by the Central Weather Bureau, Taiwan. Table I shows a statistical description of the six rainfall stations, including the station number, the longitude, the latitude, and a statistical summary of the data.

TABLE I: DESCRIPTIVE STATISTICS OF DATA SET (UNIT: MM)

\begin{tabular}{lllllll}
\hline \hline Location & Longitude & Latitude & Min & Max & Media & Mean \\
\hline Taipei & $121^{\circ} 51^{\prime}$ & $25^{\circ} 04^{\prime}$ & 21 & 425 & 146 & 164 \\
Taichung & $120^{\circ} 68^{\prime}$ & $24^{\circ} 15^{\prime}$ & 26 & 660 & 166 & 187 \\
Tainan & $120^{\circ} 18^{\prime}$ & $22^{\circ} 20^{\prime}$ & 13 & 524 & 195 & 206 \\
Hengchun & $120^{\circ} 74^{\prime}$ & $22^{\circ} 01^{\prime}$ & 17 & 489 & 214 & 232 \\
Hualien & $121^{\circ} 61^{\prime}$ & $23^{\circ} 98^{\prime}$ & 13 & 466 & 210 & 217 \\
Taitung & $121^{\circ} 15^{\prime}$ & $22^{\circ} 76^{\prime}$ & 8 & 484 & 201 & 245 \\
\hline \hline
\end{tabular}

\section{Methodology}

The generalized extreme value (GEV) distribution is based on the Gumbel, Fréchet and the Weibull distributions. It was developed by Jenkinson (1955), who combined the above three distributions (see Hosking et al., 1985, Galambos, 1987). The cumulative distribution function (cdf) of the GEV distribution is given as:

$$
\begin{gathered}
\text { Model } \mathrm{GEV}_{0}: F(x)=\exp \left\{-(1+\xi(x-\mu) / \sigma)^{-1 / \xi}\right\} \\
1+\xi(x-\mu) / \sigma>0
\end{gathered}
$$

where $\mu, \sigma>0$ and $\xi$ are the location, scale and shape parameters, respectively. The case of $\xi=0$ in equation (1) 
is defined as the Gumbel distribution:

$$
\begin{aligned}
\text { Model Gum }: F(x) & =\exp \{-\exp (-(x-\mu) / \sigma)\} \\
-\infty & <x<\infty
\end{aligned}
$$

and the sub-families defined by $\xi>0$ and $\xi<0$ correspond to the Fréchet family and the Weibull family, respectively. The maximum likelihood method was used to estimate (1) and (2) for these data, and the maximization was performed using a quasi-Newton iterative algorithm. Assuming independence of the data, the likelihood function is given as the product of the assumed densities for the observations $x_{1}, x_{2}, \ldots, n$. For the $\mathrm{GEV}_{0}$ model, we have:

$$
\begin{aligned}
& L(\mu, \sigma, \xi)=\frac{1}{\sigma^{n}} \prod_{i=1}^{n}\left(1+\xi\left(x_{i}-u\right) / \sigma\right)^{-(1 / \xi+1)} \\
& \times \exp \left\{-\sum_{i=1}^{n}\left(1+\xi \frac{x_{i}-\mu}{\sigma}\right)^{-1 / \xi}\right\}
\end{aligned}
$$

provided that $\quad 1+\xi \frac{x_{i}-\mu}{\sigma}>0, i=1, \ldots, n$

The likelihood ratio test may be used as a standard way of determining the best fitting models. In order to investigate the existence of a deterministic trend in extreme rainfall over time, we consider the following variations of Models $\mathrm{GEV}_{0}$ and $\operatorname{Gum}_{0}{ }^{1}$ :

$$
\begin{gathered}
\text { Model GEV }: \mu=a+b\left(\text { Year- }_{0}+1\right), \\
\sigma=\text { constant }, \quad \xi=\text { constant }
\end{gathered}
$$

a four-parameter model with $\mu$ allowed to vary linearly with respect to time, and "constant" means that the parameter is not time dependent but is to be estimated:

$$
\begin{gathered}
\text { Model Gum } 1: \mu=a+b\left(\text { Year- }_{0}+1\right), \\
\sigma=\text { constant }, \quad \xi=0,
\end{gathered}
$$

After the best models for the data have been determined, the next step is to derive the return levels for rainfall. The T-year return level, $x_{T}$, is the level exceeded on average only once every $\mathrm{T}$ years. If Model $\mathrm{GEV}_{0}$ is assumed, then inverting $F\left(x_{T}\right)=1-1 / T$ leads to the expression:

$$
x_{T}=\mu-\frac{\sigma}{\xi}\left\{1-[-\log (1-1 / T)]^{-\xi}\right\}
$$

If Model $\mathrm{Gum}_{0}$ is assumed, then the corresponding expression is given as:

$$
x_{T}=\mu-\sigma \log \{-\log (1-1 / T)\}
$$

On substituting $\hat{\mu}, \hat{\sigma}$ and $\hat{\xi}$ into equations (6)-(7), we

\footnotetext{
${ }^{1}$ We follow the same statistical methods as Nadarajah (2005), Feng et al. (2007), and Park et al. (2011). Consequently, some descriptions throughout this paper are the same as the above.
}

have the maximum likelihood estimates of the respective return levels.

\section{ESTIMATED RESULTS}

All the empirical results, including the estimates and their corresponding standard errors (SE), are given in Table II. It is evident that the Taipei, Taichung, Tainan and Taitung stations have consistent distributions for the two phases. The non-stationary Gumbel distribution is suitable for the Taitung station, while the stationary Gumel distribution is applicable for the Taipei, Taichung, Tainan stations for the two phases. The Hengchun station does not have a consistent distribution for the two periods. However, the Hualien station has a non-stationary GEV distribution for the period 1910-2010, but has a stationary GEV distribution for the period 1960-2010.

The Taipei and Tainan stations have a greater location

\begin{tabular}{|c|c|c|c|c|c|c|}
\hline Location & Model & Period & $\widehat{\mathrm{a}}(\mathrm{SE})$ & $\widehat{\mathrm{b}}(\mathrm{SE})$ & $\sigma(\mathrm{SE})$ & $\hat{\xi}(\mathrm{SE})$ \\
\hline \multirow{2}{*}{ Taipei } & $\mathrm{Gum}_{0}$ & $1910-2010$ & $\begin{array}{r}131.41 \\
(5.55)\end{array}$ & & $\begin{array}{l}52.84 \\
(4.12)\end{array}$ & \\
\hline & $\mathrm{Gum}_{0}$ & $1960-2010$ & $\begin{array}{r}133.04 \\
(8.39)\end{array}$ & & $\begin{array}{l}57.06 \\
(6.34)\end{array}$ & \\
\hline \multirow{2}{*}{$\begin{array}{l}\text { Tai- } \\
\text { chung }\end{array}$} & $\mathrm{Gum}_{0}$ & $1910-2010$ & $\begin{array}{r}147.26 \\
(7.09)\end{array}$ & & $\begin{array}{l}67.56 \\
(5.32)\end{array}$ & \\
\hline & $\mathrm{Gum}_{0}$ & $1960-2010$ & $\begin{array}{r}146.55 \\
(9.58)\end{array}$ & & $\begin{array}{l}65.16 \\
(7.40)\end{array}$ & \\
\hline \multirow{2}{*}{ Tai-nan } & Gum $_{0}$ & $1910-2010$ & $\begin{array}{r}165.40 \\
(7.77)\end{array}$ & & $\begin{array}{r}73.60 \\
(5.48)\end{array}$ & \\
\hline & Gum $_{0}$ & $1960-2010$ & $\begin{array}{r}167.40 \\
(9.81) \\
\end{array}$ & & $\begin{array}{r}66.41 \\
(7.03) \\
\end{array}$ & \\
\hline \multirow{2}{*}{$\begin{array}{l}\text { Heng- } \\
\text { chun }\end{array}$} & $\mathrm{GEV}_{0}$ & $1910-2010$ & $\begin{array}{r}196.33 \\
(8.78)\end{array}$ & & $\begin{array}{r}79.6 \\
(6.14)\end{array}$ & $\begin{array}{r}-0.14 \\
(0.06)\end{array}$ \\
\hline & $\mathrm{Gum}_{1}$ & $1960-2010$ & $\begin{array}{r}151.71 \\
(18.68) \\
\end{array}$ & $\begin{array}{r}64.85 \\
(32.23) \\
\end{array}$ & $\begin{array}{r}69.13 \\
(7.72) \\
\end{array}$ & \\
\hline \multirow{2}{*}{$\begin{array}{l}\text { Hua- } \\
\text { lien }\end{array}$} & $\mathrm{GEV}_{1}$ & $1910-2010$ & $\begin{array}{r}157.29 \\
(15.71)\end{array}$ & $\begin{array}{r}52.21 \\
(26.99)\end{array}$ & $\begin{array}{l}76.16 \\
(5.77)\end{array}$ & $\begin{array}{r}-0.15 \\
(0.05)\end{array}$ \\
\hline & $\mathrm{GEV}_{0}$ & $1960-2010$ & $\begin{array}{r}197.55 \\
(12.79) \\
\end{array}$ & & $\begin{array}{r}80.99 \\
(9.17) \\
\end{array}$ & \\
\hline \multirow{2}{*}{$\begin{array}{l}\text { Tai- } \\
\text { tung }\end{array}$} & $\mathrm{Gum}_{1}$ & $1910-2010$ & $\begin{array}{r}144.61 \\
(14.66)\end{array}$ & $\begin{array}{r}67.01 \\
(25.40)\end{array}$ & $\begin{array}{l}69.15 \\
(5.07)\end{array}$ & \\
\hline & $\mathrm{Gum}_{1}$ & $1960-2010$ & $\begin{array}{r}166.67 \\
(16.48) \\
\end{array}$ & $\begin{array}{r}51.34 \\
(28.18) \\
\end{array}$ & $\begin{array}{r}61.36 \\
(6.81) \\
\end{array}$ & \\
\hline
\end{tabular}
parameter for the period 1960-2010 than for the period 1910-2010, showing a slight increase in extreme rainfall for the period 1960-2010. Similarly, the Taichung station has a slight decrease in extreme rainfall for the period 1960-2010. It is clear that the empirical results indicate extreme rainfall for the Taitung and Hualien stations have had a manifest increase during the period 1960-2010.

TABLE II: Best FitTING MODELS AND PARAMETER EsTIMATES FOR 1910-2010 AND 1960-2010

Table III gives the estimates of the return level, $x_{T}$, corresponding to $10,20,50,100$ years for the locations, where the best fitting and stationary model for the period 1960-2010 was chosen. The 95\% confidence intervals for these return levels are also provided. The empirical results indicate that, given 50-year return level (for the year 2060), the return levels of daily extreme rainfall of the Taipei, Taichung, Tainan and Hualien stations were all greater than $350 \mathrm{~mm}$, reaching a warning line of extremely torrential rainfall, as defined by the CWB in Taiwan.

Fig. 1-3 shows the contour maps of the return levels for 10 , 20 and 50-years, respectively. These contour maps can assist 
in determining changes in extreme rainfall in a simple manner.

TABLE III: RETURN LEVELS ESTIMATES FOR 10, 20, 50, 100-YEARS (BASED ON 1960-2010)

\begin{tabular}{ccccc}
\hline \hline Location & 10 -year & 20 -year & 50 -year & 100 -year \\
\hline \multirow{2}{*}{ Taipei } & 261 & 302 & 355 & 395 \\
& $(143,379)$ & $(184,420)$ & $(238,473)$ & $(277,513)$ \\
Taichung & 293 & 340 & 400 & 446 \\
& $(175,410)$ & $(222,457)$ & $(283,518)$ & $(328,563)$ \\
Tainan & 317 & 365 & 426 & 472 \\
& $(128,505)$ & $(175,553)$ & $(238,615)$ & $(284,661)$ \\
Hualien & 343 & 377 & 415 & 438 \\
& $(312,391)$ & $(343,442)$ & $(374,506)$ & $(391,554)$ \\
\hline \hline
\end{tabular}

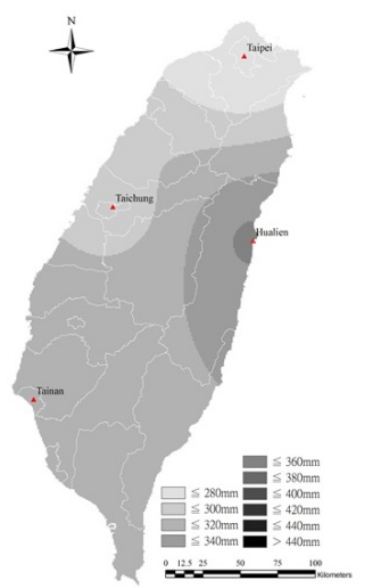

Fig. 1. Contour maps for 10-year return level

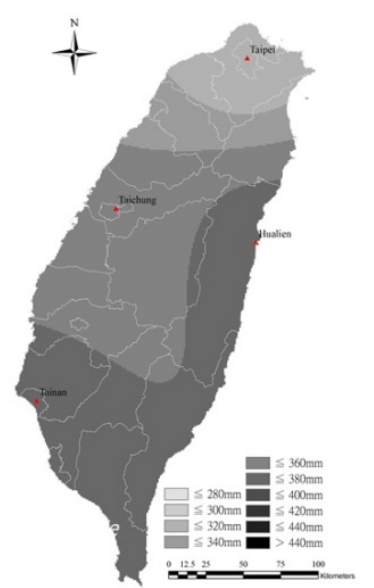

Fig. 2. Contour maps for 20-year return level

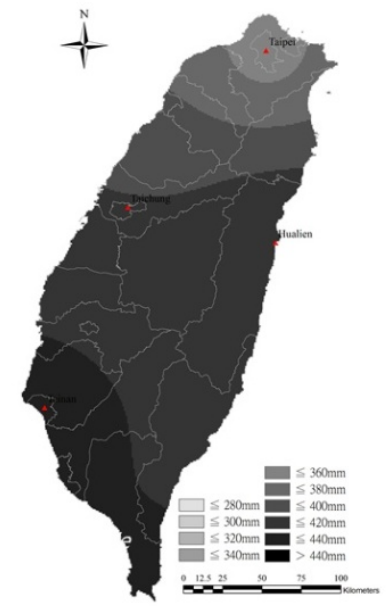

Fig. 3. Contour maps for 50-year return level

\section{CONCLUSION}

This is the first investigation to use the generalized extreme value to model extreme rainfall in Taiwan. We estimated extreme rainfall using stationary and non-stationary models for both 1910-2010 and 1960-2010 to detect changes in extreme rainfall for these two periods. The empirical results indicated that the stationary Gumbel distribution was suitable for the Taipei, Taichung, and Tainan stations, while the non-stationary Gumbel distribution was suitable for the Taitung station. Among these stations, the Taipei and Tainan stations have a slight increase in extreme rainfall, while the Taitung station shows a manifest increase in extreme rainfall for the period 1961-2010.

Given 50-year return level (for the year 2060), the return levels of daily extreme rainfall of the Taipei, Taichung, Tainan and Hualien stations were all greater than $350 \mathrm{~mm}$, reaching a warning line of extremely torrential rainfall, as defined by the CWB in Taiwan.

\section{ACKNOWLEDGMENT}

For financial support, the first and third authors are most grateful to the Taiwan Climate Change Projection and Information Platform Project (NSC 100-2621-M-492-001), and the second author wishes to acknowledge the Australian Research Council, National Science Council, Taiwan, and the Japan Society for the Promotion of Science.

\section{REFERENCES}

[1] X. Ge, T. Li, S. Zhang, and M. Peng, "What causes the extremely heavy rainfall in Taiwan during Typhoon Morakot (2009)?" Atmos. Sci. Lett., vol. 11, pp. 46-50, 2010.

[2] C.-C. Hong, M.-Y. Lee, H.-H. Hsu, and J.-L. Kuo, "Role of submonthly disturbance and 40-50 day ISO on the extreme rainfall event associated with Typhoon Morakot (2009) in southern Taiwan," Geophys. Res. Lett. vol. 37, 2010.

[3] H.-J. Chu, T.-Y. Pan, and J.-J. Liou, "Extreme precipitation estimation with typhoon Morakot using frequency and spatial analysis," Terr. Atmos. Ocean. Sci., vol. 22, no. 6, pp. 549-558, December 2011.

[4] H.-H. Chia and C. T. Lee, "The long-term variability of typhoon activity," presented at Taiwan Climate Change Conference, Taipei, 2008.

[5] J.-Y. Tu, C. Chou, and P.-S. Chu, "The abrupt shift of typhoon activity in the vicinity of Taiwan and its association with western North Pacific-East Asian climate change," J. Climate. vol. 22, pp. 3617-3628, 2009.

[6] V. T. V. Nguyen, T. D. Nguyen, and H. Wang, "Regional estimation of short duration rainfall extremes," Wat. Sci. Technol., vol. 37, pp.15-19, 1998.

[7] V. T. V. Nguyen, T. D. Nguyen, and F. Ashkar, "Regional frequency analysis of extreme rainfalls," Wat. Sci. Techno, vol. 45, pp.75-81, 2002.

[8] D. Koutsoyiannis and G. Baloutsos, “Analysis of a long record of annual maximum rainfall in Athens, Greece, and design rainfall inferences," Nat. Hazards. Vol. 22, pp. 29-48, 2000.

[9] V. Ferro, "Rainfall intensity-duration-frequency formula for India discussion," J. Hydr. Eng-ASCE, vol. 119, pp. 960-962, 1993.

[10] B. P. Parida, "Modelling of Indian summer monsoon rainfall using a four-parameter Kappa distribution," Int. J. Climato, vol. 19, pp. 1389-1398, 1999.

[11] M. Cannarozzo, F. Dasaro, and V. Ferro, "Regional rainfall and flood frequency-analysis for Sicily using the 2-component extreme-value distribution," Hydro. Sci. J., vol. 40, pp. 19-42, 1995.

[12] G. Aronica, M. Cannarozzo, and L. Noto, "Investigating the changes in extreme rainfall series recorded in an urbanised area," Wat. Sci. Technol. vol. 45, pp. 49-54, 2002.

[13] A, Crisci, B. Gozzini, F. Meneguzzo, S. Pagliara and G. Maracchi, "Extreme rainfall in a changing climate: regional analysis and hydrological implications in Tuscany," Hydrol. Process, vol. 16, pp. 1261-1274, 2002. 
[14] M. D. Zalina, M. N. M. Desa, V. T. V. Nguyen, and A. H. M. Kassim, "Selecting a probability distribution for extreme rainfall series in Malaysia," Wat. Sci. Technol. vol. 45, pp. 63-68, 2002.

[15] C. S. Withers and S. Nadarajah, "Evidence of trend in return levels for daily rainfall in New Zealand," J. Hydrol. (NZ). vol. 39, no. 2, pp. $155-166,2000$

[16] S. Feng, S. Nadarajah, and Q. Hu, "Modeling annual extreme precipitation in China using the generalized extreme value distribution," J. Meteorol. Soc. Jpn, vol. 85, pp. 599-613, 2007.

[17] S. Nadarajah and D. Choi, "Maximum daily rainfall in South Korea," $J$. Earth Syst. Sci, vol. 116, no. 4, pp. 311-320, 2007.

[18] S. Nadarajah, "Extremes of daily rainfall in West Central Florida," Climatic Change, vol. 69, pp. 325-342, 2005.

[19] J. S. Park, H.-S. Kang, Y.-S., Lee, and M.-K. Kim, "Changes in extreme daily rainfall in South Korea," Int. J. Climatol, vol. 31. pp. 2290-2299, 2011.

[20] A. F. Jenkinson, "The frequency distribution of the annual maximum (or minimum) values of meteorological elements," Quart. J. Roy. Meteor. Soc. vol. 81, pp. 158-171, 1955.

[21] J.R.M. Hosking and J. R. Wallis, "Parameter and quantile estimation for the generalized Pareto distribution," Technometrics, vol. 29, no. 3, pp. 339-349, 1987. doi:10.1002/joc.2236

[22] J. Galambos, The asymptotic theory of extreme order statistics, 2nd ed. Melbourne, Florida: Krieger, 1987

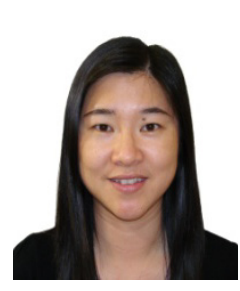

Lan-Fen Chu was born in Taichung, Taiwan on January $7^{\text {th }}$ in 1974. She got her Phd in Applied Economics from National Chung-Hsing University in 2008. Her dissertation was focused on the field of natural resources and climate changes, involving assessment of the value of coral reef under climate change, and the analysis of the water resources considering the climate change.

After getting her Phd degree, at the Institute of Economics, Academia Sinica, she worked as a poster Phd for two years, and now she has been working at the National Science and Technology Center for Disaster Reduction (NCDR) as a Project-Appointed Assistant Research Fellow. At the present, her investigation involves the project of Taiwan Climate Change Projection and Information Platform Project. Moreover, she always shows her high interest in analyzing the pattern of the extreme rainfall via statistical method, and the impact of climate change on agriculture in Taiwan.

Dr. Chu also won a medal of Phi Tau Phi within 6 years of her master's degree study. And up to now, she has published two papers on Journal of Reviews on Global Economics and Tourism Management.

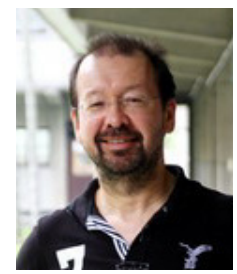

Michael McAleer holds a PhD in Economics from Queen's University, Canada. He is Professor of Quantitative Finance, Econometric Institute, Erasmus School of Economics, Erasmus University Rotterdam, The Netherlands, Distinguished Chair Professor, College of Management, National Chung Hsing University, Taiwan, Adjunct Professor in both the Department of Economics and Finance and the Department of Mathematics and Statistics at the University of Canterbury, New Zealand, and Adjunct Professor in the Faculty of Economics and Business, Complutense University of Madrid (founded 1293). He has been a distinguished visiting professor at many prestigious universities, including University of Tokyo, Kyoto University and Osaka University, Japan, University of Padova (founded 1222), Italy, Ca' Foscari University of Venice, Italy, University of Zurich, Switzerland, Chinese University of Hong Kong, and Hong Kong University of Science and Technology. He is an elected Fellow of the Academy of the Social Sciences in Australia (FASSA), International Environmental Modelling and Software Society (FIEMSS), Modelling and Simulation Society of Australia and New Zealand (FMSSANZ), Tinbergen Institute, The Netherlands, and the Journal of Econometrics. He has published more than 600 journal articles and books in econometrics, economics, statistics, finance, risk management, applied mathematics, intellectual property, environmental modelling, and related disciplines. He is presently a member of the editorial boards of 20 international journals, and serves on several as Editor-in-Chief or Associate Editor-in-Chief.

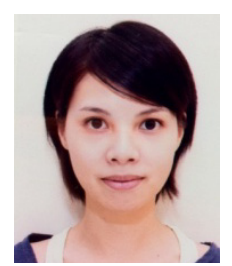

Szu-Hua Wang was born in Taipei, Taiwan, 1979. She completed her Bachelor at National Cheng-Kung University in Tainan, 2001. She got her Master degree and $\mathrm{PhD}$ degree in the field of urban and regional planning at National Taipei University in 2003 and 2010. She worked as an assistant from 2003 to 2006 and planned agricultural lands of Taiwan by land suitability analysis. After graduating from the $\mathrm{PhD}$ program, she worked as a Post-Doc in National Science Council and National Taipei University. Her research focused on land use change, hazard risk, global environmental change and climate change.

Now she is an assistant professor in Department of Urban Affairs and Environmental Planning at Chinese Culture University in Taipei. She teaches environmental investigation, analysis and plan via Geographic Information System. The relationships between land use and climate change and their effects, such as risks of extreme weathers, are her recent research interests. 